\title{
Measurement of the Attenuation of Radio Signals by Jungles
}

\author{
Jack W. Herbstreit and W. Q. Crichlow
}

\section{Contribution From the Central Radio Propagation Laboratory, National Bureau of Standards, Boulder, Colo.}

\author{
(Received March 27, 1964; revised April 10, 1964)
}

\begin{abstract}
Recent interest in jungle communications has indicated the desirability of publishing quantitative field strength measurements made in jungles by the authors during World War II. The jungle attenuation of radio signals is so great that for satisfactory communications over distances greater than one mile, skywave propagation or elevated antennas should be employed.
\end{abstract}

\section{Introduction}

A part of World War II was conducted in jungle territory in the Southwest Pacific area. In 1943, the authors were members of Dr. W. L. Everitt's Operational Research Staff in the Office of the Chief Signal Officer, Department of the Army, Washington, D.C. In this capacity they conducted a communications research study and quantitative field measurements of radio propagation through jungles in the rain forests of Panama and New Guinea. The results obtained are given in Signal Corps reports [Herbstreit and Crichlow, 1943; Bateman, Herbstreit, and Zechiel, 1944; War Department, 1944] but are not generally available. Portions of these results are published at this time because of recent interest in radio propagation through jungles. It is believed that the conclusions reached are still valid. The original Signal Corps reports contain measurements of atmospheric noise levels in jungle areas and applications of both the attenuation and noise measurements to the evaluation of the performance of particular transmitting-receiving set performance. A more comprehensive atmospheric noise study has been made following these original results and is available [CCIR, 1963a; Crichlow, Disney, and Jenkins, 1957].

\section{Jungle Attenuation Measurements}

In order to determine the magnitude of the attenuation of radio waves caused by jungle growth, measurements were made in Panama and New Guinea of field strength versus distance at several frequencies. The jungles of both Panama and New Guinea where the measurements were conducted were dense rain forests with many tall trees and thick, almost impenetrable low level foliage of palms, bamboo, and other plant life interspersed. In Panama the average tree height was approximately $50 \mathrm{ft}$, and the thick foliage 10 to $30 \mathrm{ft}$. Generally, in order to install the equipment at measuring points in the Panama jungles it was necessary to cut paths through the undergrowth perpendicular to the propagation path. In the jungles selected for measurements in New Guinea, the trees were appreciably taller, ranging upwards to $90 \mathrm{ft}$; however, the undergrowth was not quite as thick and inaccessible as that in Panama.

Low power transportable Signal Corps transmitters on frequencies of $2005 \mathrm{kc} / \mathrm{s}, 3010 \mathrm{kc} / \mathrm{s}, 5880 \mathrm{kc} / \mathrm{s}$, $5975 \mathrm{kc} / \mathrm{s}, 44 \mathrm{Mc} / \mathrm{s}$, and $98.8 \mathrm{Mc} / \mathrm{s}$ were used with vertical whip antennas near the ground on all frequencies except $98.8 \mathrm{Mc} / \mathrm{s}$. At $98.8 \mathrm{Mc} / \mathrm{s}$, a halfwave dipole mounted on an $18 \mathrm{ft}$ mast was used with both horizontal and vertical polarization. Calibrated field strength meters were used at all frequencies for the measurements.

In order to obtain a measure of the radiated power of each transmitter-antenna combination, field strength versus distance measurements were made in Panama over flat open ground (golf course). The ground conductivity and dielectric constant of the ground were estimated by comparing the measurements with theoretical curves of field strength versus distance computed for several electrical ground constants.

Next, the transmitters were taken into the jungle and measurements of field strength versus distance were made at a number of distances along a radial path from the transmitters. On $44 \mathrm{Mc} / \mathrm{s}$, a continuous recording of field strength versus distance, which gives a picture of the large variations of the field strength encountered in the jungle, was made as the transmitter was carried along a narrow jungle trail. Similar measurements of field strength versus distance were made on frequencies of 3390 and 6070 $\mathrm{kc} / \mathrm{s}$ in the New Guinea jungle using Signal Corps transmitters similar to those used in Panama for these frequencies. Figures 1, 2, and 3 show the results of the Panama measurements, and figure 4 the New Guinea results. These results are shown in terms of the field strengths measured for the particular Signal Corps target transmitters used and in terms of transmission loss [CCIR, 1963b] which is independent of transmitting and receiving equipment.

Figure 1(a) shows measurements of field strength versus distance at $2005 \mathrm{kc} / \mathrm{s}$ over the golf course and also in the jungle. At this location the jungle ended 
at 1.6 miles, and the land was open and clear beyond this point. It may be noticed that the field strength did not fall off very rapidly after the end of the jungle was reached. The presence of skywave is not indicated since no fading was noticed at any of the dis-

(NOMINAL TRANSMITTER POWER OUTPUT $=25$ WATTS)

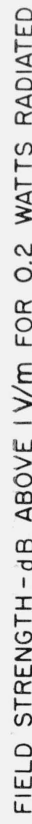

(a) $2005 \mathrm{Kc} / \mathrm{s}$
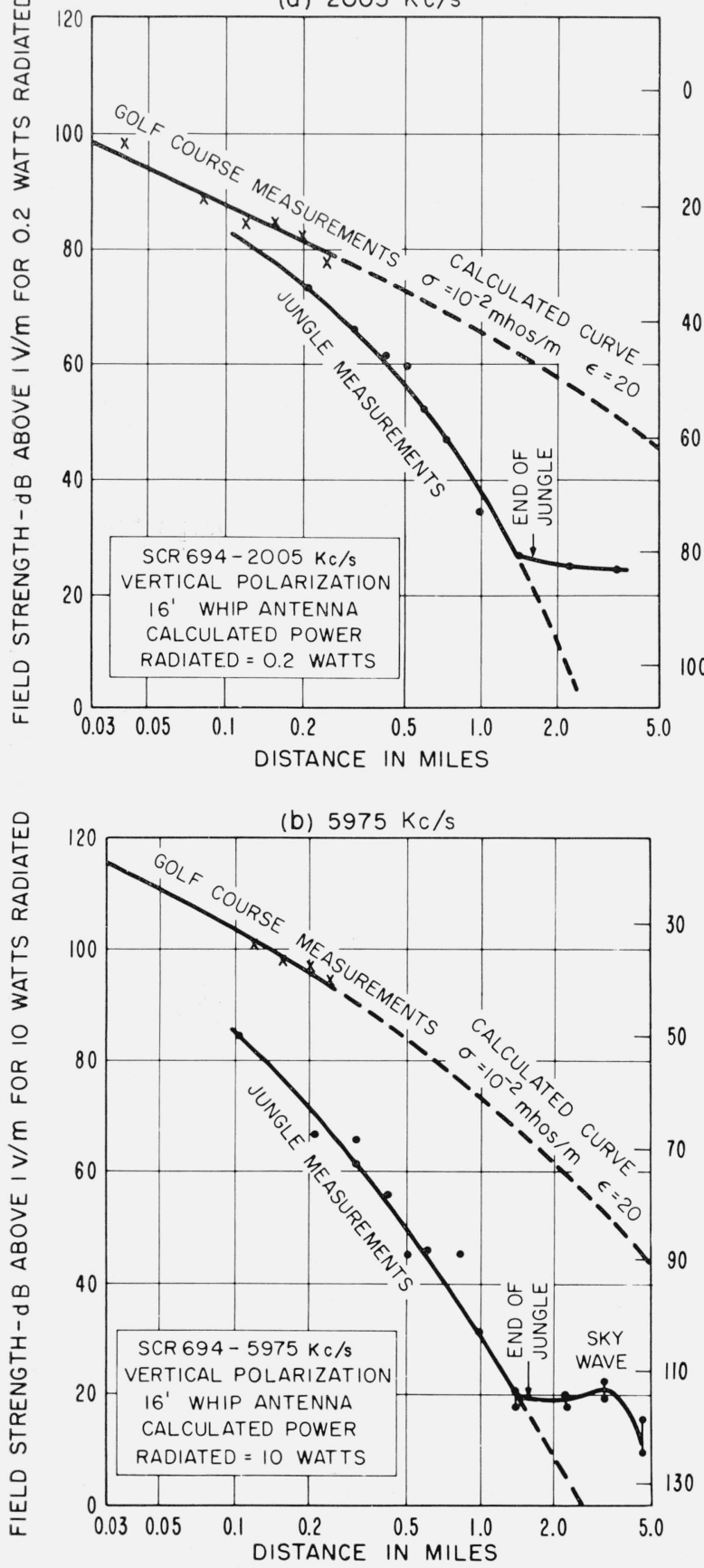

Figure 1. Measurements of field strength or transmission loss versus distance over flat ground (golf course) and through jungles of Panama. tances at which measurements were made. The dashed line on the jungle curve of figure 1 (a) is an estimate of the way the field strength would have fallen off at greater distances if the jungle had not ended.

(NOMINAL TRANSMITTER POWER OUTPUT $=1.0$ WATT)

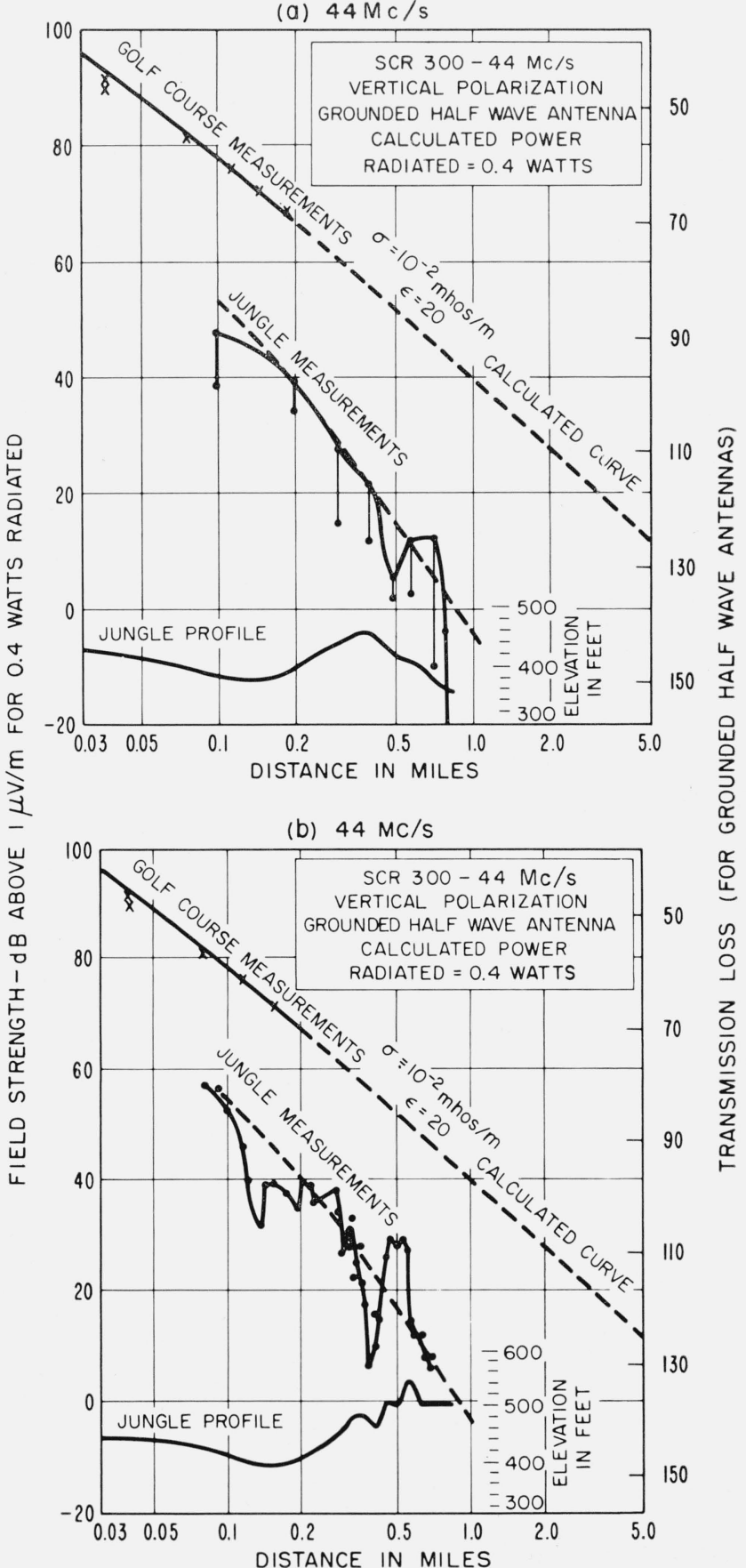

FIguRE 2. Measurements of field strength or transmission loss versus distance over flat ground (golf course) and through jungles of Panama. 

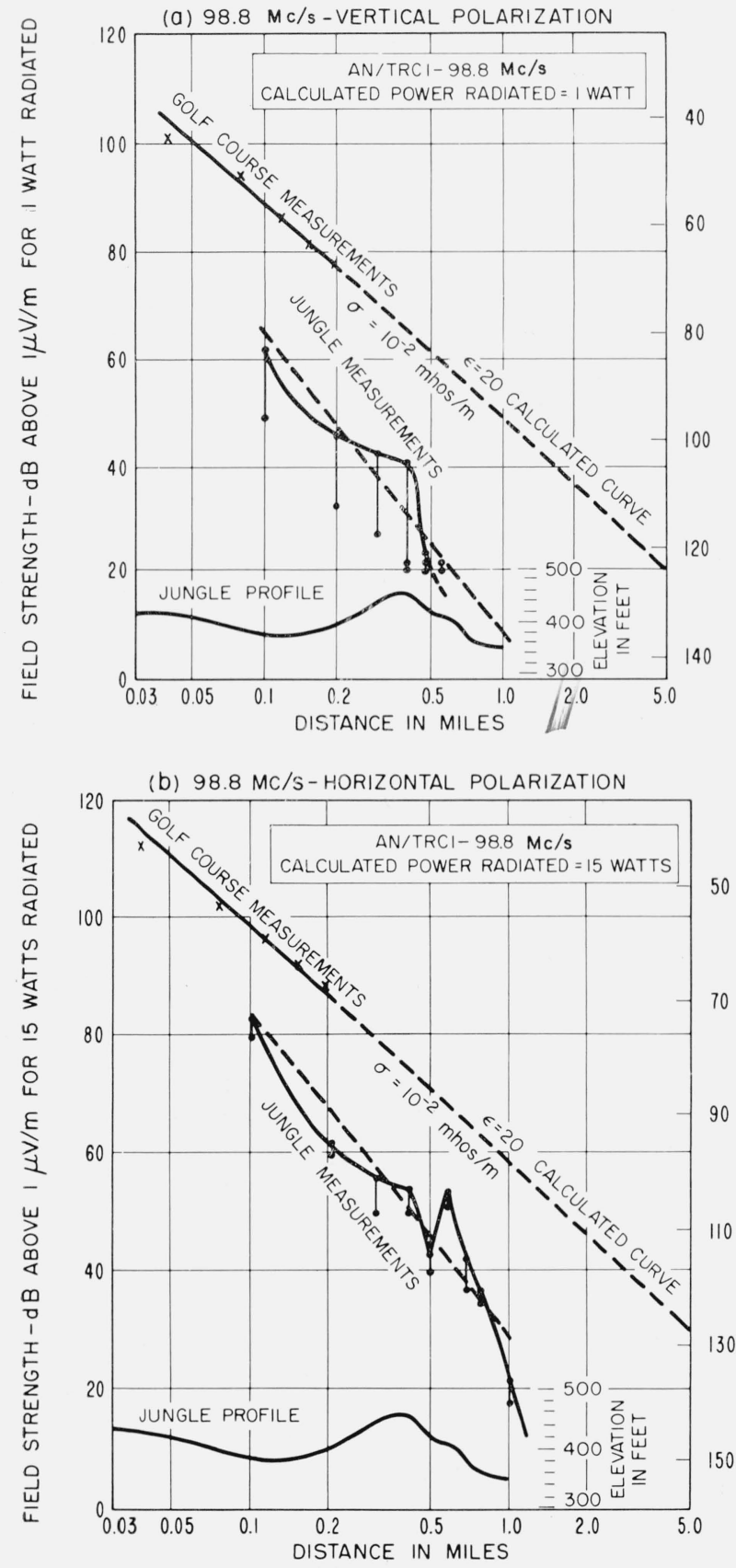

TRANSMITTER ANTENNA HEIGHT $=18$ FEET RECEIVER ANTENNA HEIGHT $=10$ FEET

Figure 3. Measurements of field strength or transmission loss versus distance over flat ground (golf course) and through jungles of Panama.
(NOMINAL TRANSMITTER POWER OUTPUT = 25 WATTS)

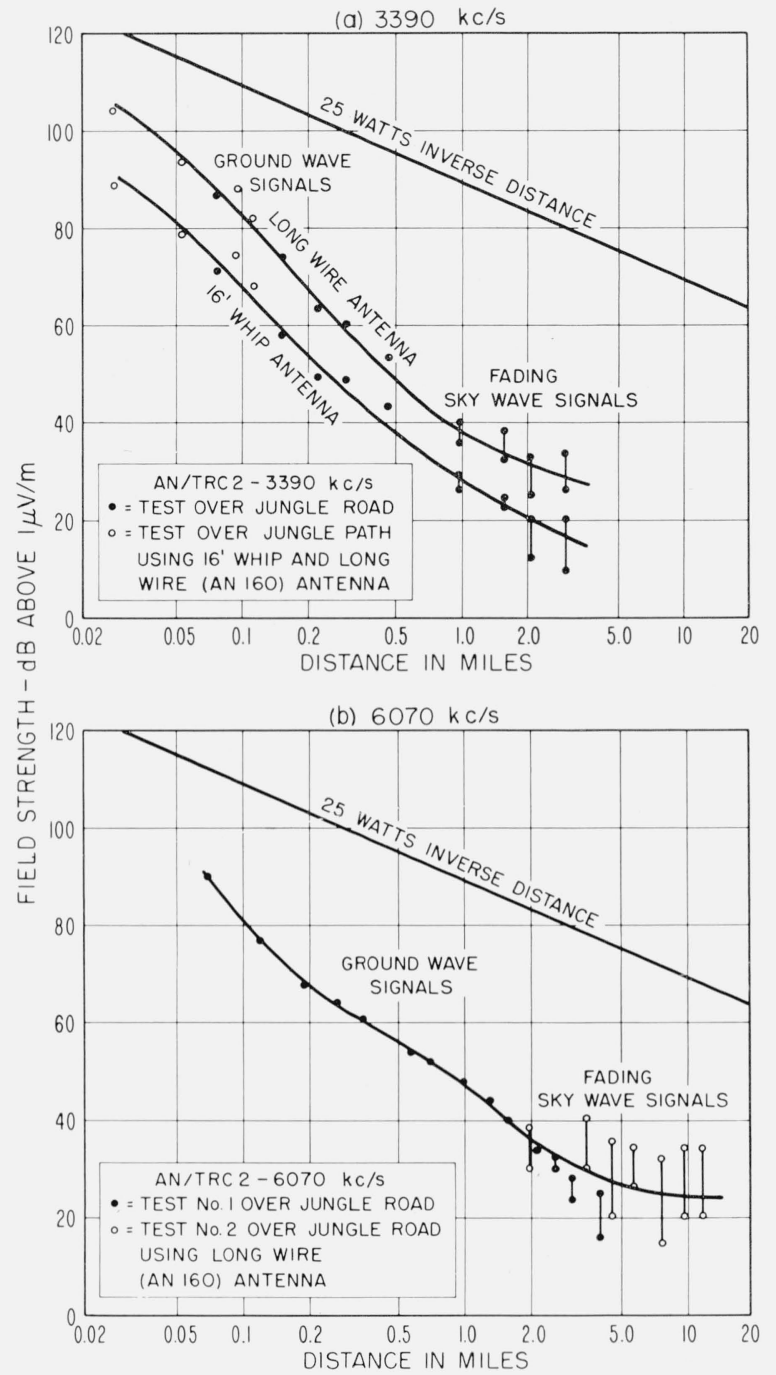

FiguRE 4. Measurements of field strength versus distance through jungles of New Guinea.

Figure 1(b) gives the results of measurements on $5975 \mathrm{kc} / \mathrm{s}$. At this frequency, fading was noticed at a little over 1 mile from the transmitter, and the field strength did not fall off at distances greater than 1 mile. This indicates that skywave was becoming an appreciable part of the received signal even though a short vertical antenna was being used on the transmitter.

The measurements at $44 \mathrm{Mc} / \mathrm{s}$ show that the elevation of the intervening terrain as well as the jungle growth have a marked effect on the strength of the received signal. Profiles of the actual terrain elevation, without regard to the tree heights, are plotted on figure 2 below the corresponding field strength measurements. Figure 2(a) shows the point to point measurements made in dense jungle, and figure 
2(b) shows data taken along a jungle trail. It may be seen that the field strength roughly follows the ground profile. Both the maximum and minimum field strength measurements at each location are plotted on figure 2, and the solid line drawn through the measurements is through the maximum values. The dashed lines through the jungle measurements on figure 2 (a) and (b) are estimates of the field strength versus distance if the jungle were level. It is interesting to note that the same dashed line can be drawn through the point-to-point measurements and those made along the jungle trail. It is found that in a particular location a variation of as much as 4 to 1 in field strength is obtained simply by moving the receiving antenna a few feet.

On $98.8 \mathrm{Mc} / \mathrm{s}$ the effect of the terrain elevation is also very marked, and the field strength again roughly shows the jungle profile. Considerable difference exists in both attenuation and field strength variation between horizontal and vertical polarization in the jungle. The vertically polarized fields are attenuated more rapidly and show more variation in strength than do the horizontally polarized fields. Figure 3 shows that the horizontally polarized fields are approximately $15 \mathrm{~dB}$ less than vertically polarized fields at a distance of 1 mile. Because of the magnitude of jungle attenuation found at low antenna heights, the effect of elevating the antennas above the jungle growth was investigated for a frequency of $44 \mathrm{Mc} / \mathrm{s}$ and a distance of 0.4 mile. These measurements indicate that the received field strength increases approximately $12 \mathrm{~dB}$ with the transmitting antenna raised to an elevation of $50 \mathrm{ft}$, the average height of intervening jungle growth being approximately $50 \mathrm{ft}$. When both antennas are raised into trees, one $50 \mathrm{ft}$ and the other $70 \mathrm{ft}$ above the jungle floor, an increase of approximately $23 \mathrm{~dB}$ is obtained over that when both antennas are essentially at ground level.

Figure 4 shows similar measurements of field strength versus distance made in the rain forest jungles near Oro Bay, New Guinea, on frequencies of $3390 \mathrm{kc} / \mathrm{s}$ and $6060 \mathrm{kc} / \mathrm{s}$. The jungles at this location were said to be typical of the rain forest type of jungle found in most of New Guinea. The undergrowth in this jungle was not as dense as the undergrowth in the Panama jungle through which the previous measurements were made; however the high trees were considerably taller than those in Panama.

\section{Effective Range of Communications}

To determine the effective range of particular transmitting and receiving systems, it is necessary to know the magnitude of the required field strengths in each case; and these, in turn, depend upon the levels of the received external noise and the noise generated in the receiver, as well as the kinds of signal modulation used. Up to frequencies the order of $30 \mathrm{Mc} / \mathrm{s}$, atmospheric noise is expected to be the controlling factor at these low latitudes where jungles are encountered, and at higher frequencies galactic or set noise is expected to limit communica- tions [CCIR 1963a, 1963c]. Both the received signal level and the received atmospheric noise level are expected to depend to a certain extent on the polarization and directivity of the receiving antennas, as well as their heights above or below the height of the jungle growth. An analysis of these factors in terms of the signal strength required for satisfactory communication for the particular sets used was included in the original Signal Corps reports. This analysis indicated that with the equipment used in the tests, communication via groundwave through the jungle for distances greater than approximately 1 mile is virtually impossible. Because of the high rate of measured groundwave attenuation with distance, considerable increase in power would be required to extend this groundwave range appreciably. However, it was demonstrated that satisfactory communication by means of skywave transmission could be obtained at greater distances by using long wire skywave antennas when transmitting on frequencies reflected by the ionosphere. It should be noted that when using skywave frequencies for jungle communications, interference to and from other stations at considerable distances is possible. Ionospheric predictions are useful for obtaining optimum results.

\section{Conclusions}

Attenuation due to dense jungle growth is so great that for communication over distances greater than approximately 1 mile the groundwave which is normally employed for these ranges is practically useless. Jungle communication greater than 1 mile may be obtained by elevating antennas of VHF sets either by raising them into trees or by using hilltop sites. At VHF, horizontal polarization was found to be preferable because of its lower absorption rate. Ranges greater than 1 mile using medium or high frequencies were found to require skywave transmission using antennas radiating energy almost vertically on frequencies reflected by the ionosphere.

\section{References}

Bateman, Ross, Jack W. Herbstreit, and Robert B. Zechiel (1944), Measurement of factors affecting radio communication and loran navigation in SWPA, Report No. ORB-2-4, Office of the Chief Signal Officer, Washington, D.C.

CCIR Report 322 (1963a), World distribution of characteristics of atmospheric radio noise, Documents of the Xth Plenary Assembly, ITU, Geneva; revision of Report 65, Revision of atmospheric radio-noise data, meeting in Los Angeles 1959.

CCIR Recommendation 341 (1963b), The concept of transmission loss in studies of radio systems, ITU, III, Geneva. CCIR Recommendation 339 (1963c), Bandwidths and signalto-noise ratios in complete systems, ITU, III, Geneva.

Crichlow, W. Q., R. T. Disney, and M. A. Jenkins (1957), Quarterly radio noise data, NBS Technical Note 18-1 and supplements.

Herbstreit, Jack W., and W. Q. Crichlow (1943), Measurement of factors affecting jungle radio communication, Report No. ORB-2-3, Office of the Chief Signal Officer, Washington, D.C.

War Department (1944), Technical Bulletin SIG 4.

(Paper 68D8-388) 